\section{Post-mortem on failure}

\section{Moscow}

FATE has dealt the Phobos project some cruel blows. Last September, due to an operator's error and its consequences, the first spacecraft was lost. So researchers' hopes were pinned on Phobos 2, the second of the two spacecraft aimed at orbits about Mars and its moon Phobos. But when the second probe approached the surface of Phobos, the onboard transmitter fell silent. Attempts to save the spacecraft were unsuccessful. So was it a complete failure or just a partial setback?

The project directors exposed themselves to criticism by their silence during the critical period. Information for the press dried up. No doubt, in the past, the whole affair would have been passed over in silence, but public pressure is now so strong that the engineers and scientists were eventually compelled to meet journalists and give an explanation.

Two opposing opinions stand out. Technical specialists believe that Phobos accomplished its main tasks, but scientists are convinced that the spacecraft had serious defects. This is a classic conflict between the manufacturer and the consumer, in this case between industry and science. Readers may be able to draw their own conclusions.

Vyacheslav Kovtunenko, the project's technical director, says that when it was decided in 1980 to embark on the comprehensive exploration of Venus, Mars, the Moon and the asteroids, the question arose whether to design a special space vehicle for each object or an all-purpose platform that could, with modification, explore them all. The second option offered benefits, and was approved.

Kovtunenko says that the Phobos project has shown that spacecraft built around a standard platform can perform complex tasks at the distance of Venus or Mars, bring soil samples from the Moon's far side and investigate the far side of the Sun. But he acknowledges that there were malfunctions and design defects, adding that these are inevitable in such complex projects.

Academician Roald Sagdeev, the project's scientific director, sharply disagrees. He noted that the successful Vega project (to Halley's comet) had been "up to the mark" and that, by carrying instruments from scientific organizations in nine countries, Vega had brought Soviet science "credit" and prestige.

Sagdeev said that the collaborators from 13 countries in the Phobos project had had to "overcome the resistance of financial bodies and, often, political resistance from opponents of the new thinking", particularly of the expansion of contacts with the Soviet Union. "We were sure that Soviet technology would give of its best", but "it seems that perestroika has not reached that sphere".

Sagdeev also disagreed with Kovtunenko's "confident conclusion", saying that the essence of the project had been the exploration of Phobos. "The most original ideas and technological solutions were invested in this part of the programme, which has not been fulfilled."

Referring to his candidacy in the elections for the People's Chamber of Deputies, Sagdeev said that one of the points in his election programme was "the struggle for the restoration of the people's trust in space programmes". He hoped that the future Supreme Soviet of the USSR would uphold the interests of its electors in space research. "We'll have no future without space exploration", but "our style" must change.

Vladimir Pochukayev, head of the Phobos ballistics group, stressed the difficulty of the venture. The orbit of Phobos had been uncertain by hundreds of kilo-

\section{IMAGE UNAVAILABLE FOR COPYRIGHT REASONS}

Elusive moon - a Viking orbiter photomosaic of Phobos.

metres, but the spacecraft's flights had allowed it to be refined to within two or three kilometres. As well as photographing Phobos, the spacecraft had also studied the second martian moon, Deimos, the coordinates of which had been fixed with an accuracy of tens of kilometres. "I believe that ballistics experts have performed their task", Pochukayev said.

On the scientific programme, Professor Albert Galeyev, director of the Soviet Academy of Sciences' Institute of Space Research, said that the first stage of the project had been carried through successfully. X-ray images of the Sun had revealed solar flares whose intensity was exceeded only by the record outbursts of 1972. The magnetic field of Mars had been measured, as well as its radiation belts. But lack of time had meant that some studies had been unfinished.

On Mars itself, Professor Vasily Moroz explained that Phobos instruments had obtained data on minerals containing water of crystallization as well as on the atmosphere. A thermal chart of a part of the martian surface had been made. But, he added, the Phobos spacecraft are "inferior in some respects to US interplanetary probes".

Professor Vladimir Lapygin, a specialist in control systems, made an organizational point. Noting that projects now "apparently need a scientific director", he complained: "we cannot say that someone is responsible for instruments, while others are responsible for the other and more complicated components".

Dr Arnold Selivanov said that the Phobos radio complex was an order of magnitude better than on any previous space probe, but that because it takes a signal 30 minutes to cover the distance between the Earth and Mars and back, it is impossible to control a probe remotely. The Phobos probe, he said, had insufficient independent compensating intelligence, yet even so it came close to success.

Selivanov praised the infrared scanning device mounted on Phobos 2 "at the very last minute", describing it as a thermal television set made by enthusiasts. Apart from thermal charts of Mars, the instrument had revealed the shadow of Phobos on the surface of the planet.

The full repercussions of the Phobos failure are not yet clear, according to Alexander Dunayev, chief of the Soviet Space Agency (Glavkosmos), who explained that future projects are now being re-examined. The fate of the Mars94 project is not yet decided, while a decision on whether to carry out a regular cycle of studies of Mars in 1995 will apparently be taken in May.

The cost of the project is also much discussed. Yuri Koptev, a department chief of the Soviet Ministry of General Machine Building, says the overall cost was 272 million roubles, including the manufacture of Soviet instruments, the space probes themselves ( $\mathrm{Rb} 51$ million), the booster rockets, preparations for the launch and even the improvement of two powerful 70-metre radio telescopes in Yevpatoriya and Ussuriisk.

But Roald Sagdeev was quick to add to this "the equivalent of $\mathrm{Rb} 60$ million in hard currency", what 150 enterprises abroad had spent on the manufacture of scientific instruments.

So what went wrong? Roald Kremnev, one of the project leaders, says that the last telemetry data showed the spacecraft to be spinning without proper altitude control. "Had one, two or three systems gone out of order?" One possibility is that the swarm of small objects about Phobos was responsible. Certainly some alien object appeared in the field of view of the stellar sensor towards the end. Was that a part torn away from the spacecraft or a piece of asteroidal material? Kremnev says that only continued analysis of the telemetry will make it possible to decide.

Mikhail Chernyshov, Novosti 